\title{
LIBERALISMO Y SOCIALISMO
}

Nancy Ochoa Antich ${ }^{*}$

\section{Resumen}

En el presente ensayo se parte de la igualdad biológica (genética), según la cual todos los humanos pertenecemos a la misma especie animal, de manera que en esa afirmación se encuentra implícita la igualdad esencial (filosófica), a pesar de que también haya diversidad entre los humanos en otros sentidos. Luego, se aborda la noción de igualdad política en el pensamiento liberal, que puede resumirse en que humanos diferentes tenemos iguales derechos o somos iguales ante la ley. Aquí encontramos implícito el tratamiento abstracto que se da a los humanos en el pensamiento moderno, pues en la igualdad ante la ley se hace abstracción de todas las cualidades concretas. Así, el ensayo propone que hay continuidad teórica entre el pensamiento liberal y el socialista, de tal manera que este último se caracteriza por tratar de que las sociedades proporcionen a los ciudadanos las condiciones

* Doctora en Filosofía (Pontificia Universidad Católica del Ecuador, PUCE), Magíster en Ciencias Políticas (PUCE). Ha sido profesora de Filosofía en la PUCE durante 28 años. Sus áreas de especialización son: Teoría del Conocimiento, Filosofía Moderna, Filosofía Latinoamericana, Filosofía Política. Ha publicado: La mujer en el pensamiento liberal, Quito, El Conejo, 1987; El Arielismo en el Ecuador, Quito, Corporación Editora Nacional, s/f., y diversos artículos en revistas especializadas. 
concretas (económicas, sociales, políticas) que garanticen una vida realmente igualitaria. Por eso, se dan ejemplos modernos pre-liberales y liberales que muestran la continuidad teórica con el pensamiento socialista. Así se pueden entender los desarrollos ideológico-políticos, como la social-democracia, y más recientemente, en América Latina, el socialismo del siglo $X X I$. No es incoherente que el socialismo politico se realice en el marco del capitalismo y actualizando los principios de la democracia liberal.

\section{Igualdad y diversidad}

Hay una sola especie humana, a pesar de que la noción de 'raza' implica que hay grupos humanos tan diversos biológicamente que se justificaría una clasificación. Las investigaciones genéticas recientes muestran que las clasificaciones de los humanos por raza son incorrectas. Es cierto que hay diferencias fisonómicas debidas a circunstancias climáticas y de alimentación. Pero los efectos son azarosos, de manera que un individuo puede parecerse fisonómicamente más a algunos de otra etnia que a muchos de la propia. Desde siempre ha habido mestizajes muy generalizados en todas las áreas de la tierra. La noción de 'etnia' es más adecuada porque no se refiere a una realidad biológica sino cultural.

De todas maneras sí hay diversidad entre humanos en otros sentidos. Para dar algunos ejemplos: 1. Los dos sexos somos anatómicamente diferentes y hay, además, varias orientaciones sexuales. 2. Las culturas son maneras tan distintas de ver el mundo que la Torre de Babel resulta ser una precisa simbolización de este hecho. La multiplicidad de cosmovisiones es real, a pesar de que las culturas, siempre mestizas, no sean esencias metafísicas sino historias sujetas a variación en el tiempo. 3. Las apariencias fí- 
sicas individuales son tan variadas que su número parece infinito y, algo que es mucho más importante, la experiencia vital de cada individuo es única. Entonces, en la realidad somos iguales y diversos al mismo tiempo: igualmente humanos; sexual, cultural e individualmente diferentes, sin que estos ejemplos agoten las posibilidades.

Recordemos además que todas las sociedades se han organizado según una desigualdad que se puede distinguir de la diversidad real. Esta distinción la aclara muy bien Rousseau: "la igualdad que la naturaleza ha establecido entre los hombres y la desigualdad que ellos han instituido" (Rousseau, 1972: 8). Esta última es una relación de poder entre grupos, una desigualdad social o convencional porque la establecen las sociedades, de acuerdo a códigos culturales y políticos. La diversidad real y la desigualdad social no siempre corresponden, tal es el caso de las clases sociales en países étnicamente homogéneos, aunque esta homogeneidad sea siempre relativa. También es lo que ocurre en la época moderna, es decir, en la época de los Estados nacionales, cuando puede haber países menos poderosos cuyo componente étnico sea más o menos el mismo de otros más poderosos.

Pero ha sido muy común la correspondencia entre diversidad real y desigualdad social, tal es el caso de las etnias dominadoras o dominadas, como los conquistadores europeos y los indígenas americanos o los esclavos de origen africano, en ese contexto histórico. Algo similar se puede afirmar de los dos sexos, ya que la subordinación de las mujeres ha sido más o menos constante. También las otras orientaciones sexuales distintas a la heterosexualidad han sido frecuentemente discriminadas, aunque no sea fácil generalizar en cuanto a otras épocas y sociedades. 


\section{La noción europea-moderna de igualdad política}

El apoyo ideológico del ascenso histórico de la burguesía fue la noción de igualdad política: la idea de que cualquiera tiene la posibilidad de aspirar a mayor poder social. La 'sangre' o la 'nobleza', en la medida en que son características supuestamente permanentes, van perdiendo validez a partir de entonces. La teoría burguesa es que humanos socialmente desiguales tengan los mismos derechos o que sean iguales ante la ley, lo cual sólo significa que haya la posibilidad no necesariamente realizada, de alcanzar mayor poder o de ascender en la jerarquía social.

Como ejemplo de argumento a favor de la igualdad política, voy a referirme a un texto del siglo XVII. En las Meditaciones Metafísicas (Descartes, 1971: 64-65), Descartes sostiene que la única certeza es el pensar, porque dudar es pensar, de manera que de lo único que no puedo dudar es del pensar. Tal razonamiento está ligado a la tesis de que cada individuo humano es una cosa que piensa, es decir, que nuestra identidad es el pensar. No soy mi cuerpo, no soy las cualidades concretas que me caracterizan y me diferencian de otros cuerpos, experiencias vitales, circunstancias materiales, contextos culturales, históricos o sociales. Soy algo que es igual a través de las diferencias. En el Discurso del Método este filósofo afirma que "el poder de juzgar bien y de distinguir lo verdadero de lo falso, que es lo que denominamos buen sentido o razón, es igual en todos los hombres". (Descartes, 2007: 35).

Actualmente es usual escuchar opiniones contrarias. Se dice que una noción de igualdad como la de este filósofo francés, es excluyente. Se argumenta que hay humanos con discapacidades mentales. Se afirma que tal noción de igualdad es el mecanismo de los conquistadores para excluir otras maneras de ser. Sin embargo, no es cier- 
to que la diversidad sea tal que dejemos de ser humanos. Éste es el universal abstracto (lo que Descartes llama "cosa que piensa").

La importancia del universal abstracto es que trae como consecuencia que todos seamos iguales ante la ley. Nombre, familia, capacidad mental, características físicas, sexo, opción sexual, etnia, condición social, no son relevantes. Ésta es la igualdad política promovida por la burguesía europea, gracias a la cual podemos cuestionar que haya jerarquías sociales basadas en el poder de los grupos. Es absurdo que, para oponerse a que haya discriminación, se niegue esta noción de igualdad. Es lógico decir que, si somos iguales en algún sentido (por ejemplo, los humanos constituimos una sola especie o, en lenguaje cartesiano, todos somos humanos), entonces tenemos iguales derechos.

\section{El tema de la propiedad privada}

Supongo que alguien pensará que lo dicho hasta ahora es muy abstracto, que hay cuestiones concretas, principalmente la propiedad privada, que instituyen la desigualdad social. Se dirá, además, que la burguesía en general (no solamente la europea, pues el capitalismo es un sistema económico mundial) ha sido y es la clase social dominante de la que hablaban Marx y Engels precisamente porque es un grupo integrado por propietarios.

No se puede desconocer el hecho de que para la burguesía este tema era y es fundamental. Pero también es indudable que en otras épocas y sociedades ha habido propiedad privada y desigualdad social. Tal situación no depende exclusivamente del capitalismo. Lo interesante, sin embargo, es que hubo pensadores europeos-modernos que plantearon la abolición de la propiedad privada. 
Recordemos primero a Tomás Moro, a su Utopía, un texto tan remoto como las primeras décadas del siglo XVI, cuando ya la burguesía iniciaba su ascenso histórico, muy influida, además, por la reciente llegada de algunos europeos al continente que llamaron Nuevo Mundo, es decir, América. Los conquistadores y colonizadores pusieron sus esperanzas en aquel lugar que creyeron nuevo. Allí podrían realizar lo que no tenían en Europa: abundancia, salud, igualdad política, libertad religiosa, paz...

Es clara la vinculación entre la burguesía y la ciudad. La misma palabra lo indica, pero también otros términos, como 'civilización' o 'urbanidad', que expresan la forma cultural en que esa clase social se ha relacionado con la vida. Pues bien, como ejemplo de los ideales de los primeros burgueses europeos, veamos cómo en la ciudad llamada Utopía no había propiedad privada:

Las calles están dispuestas y construidas muy confortable y bellamente tanto para el tráfico como para estar protegidas de los vientos. Las casas son de bella y suntuosa construcción y se extienden juntas al lado de la calle en una extensa fila, sin ninguna partición o separación. Las calles tienen una anchura de veinte pies. En la parte trasera de las casas hay amplios huertos. Cada casa tiene dos puertas, una a la calle y una secundaria en la parte posterior, que da al jardín. Estas puertas están hechas con dos hojas nunca cerradas ni con el cerrojo echado, tan fáciles de abrir que responden al mínimo tirón del dedo y se cierran solas de nuevo. Quien quiera puede entrar, pues no hay nada dentro de las casas que sea privado o propio de nadie. Y cada diez años cambian de casa por sorteo. (Moro, 1984: 56-57).

Mencionemos también a Rousseau, el ginebrino, quien en su Discurso sobre el origen de la desigualdad entre los hombres, obra emblemática de la atmósfera política que 
se respiraba en Europa en el siglo XVIII, denuncia que la propiedad privada es la causa de la desigualdad social. Muy conocido es el siguiente texto:

El primer hombre que, después de haber cercado un terreno, tuvo la ocurrencia de decir: Esto es mío, y se encontró con gente tan simple como para creérselo, fue el verdadero fundador de la sociedad civil. Cuántos crímenes, guerras, asesinatos, cuántas miserias y horrores habría ahorrado al género humano quien, arrancando las estacas o rellenando la zanja, hubiese gritado a sus semejantes: ¡No escuchéis a este impostor, estáis perdidos si olvidáis que los frutos son de todos, y que la tierra no es de nadie! (Rousseau, 1972: 75).

En realidad, cuando aparece el Manifiesto Comunista en el siglo XIX, la abolición de la propiedad privada ya había sido planteada en varias ocasiones. Además, el pensamiento de Marx y Engels puede ser considerado tan utópico como los de Moro y Rousseau, aunque se presente bajo una forma más empírica supuestamente científica. Se trata, sin duda, de la siguiente táctica discursiva: como la ciencia es verdadera, si una ideología se presenta como ciencia, tiene más posibilidades de convencer, de ganar adeptos.

No es necesario entrar en una discusión epistemológica para reconocer que es utópico afirmar, por un lado, que "La historia de todas las sociedades hasta nuestros días es la historia de las luchas de clases" (Marx y Engels, 2005: 97) y creer, por el otro, en "la desaparición definitiva de los antagonismos de clases” (Marx y Engels, 2005: 147).

Consideran Marx y Engels que el conflicto entre burguesía y proletariado es el último en la lucha de clases porque los proletarios no tienen propiedad privada, de manera que están obligados a abolirla para dar por terminado todo antagonismo: 
Los proletarios no pueden conquistar las fuerzas productivas sociales sino aboliendo el modo de apropiación en vigor; $y$, por tanto, todo modo de apropiación existente hasta nuestros días. Los proletarios no tienen nada que salvaguardar; tienen que destruir todo lo que hasta ahora ha venido garantizando y asegurando la propiedad privada existente. (Marx y Engels, 2005: 144).

Ellos también creen que "En la misma medida en que sea abolida la explotación de un individuo por otro, será abolida la explotación de una nación por otra”, que "al mismo tiempo que el antagonismo de las clases en el interior de las naciones, desaparecerá la hostilidad de las naciones entre sí” (Marx y Engels, 2005: 124-125), lo cual recuerda a Kant, otro pensador liberal europeo, y su escrito Hacia la paz perpetua (Kant, 2005), cuyo derecho cosmopolita implica la igualdad política de los humanos como fundamento teórico.

El rasgo utópico de algunas afirmaciones de Marx y Engels en el Manifiesto Comunista, nos lleva a mencionar a los llamados 'socialistas utópicos', Saint-Simon, Fourier y Owen. Precisamente la clasificación entre 'socialismo utópico’ y ‘socialismo científico’ se debe a Engels, en uno de sus deslices 'positivistas'. Es decir, es positivista un pensamiento que otorga excesivo valor a las ciencias empíricas, pues al mismo tiempo denigra a otras formas de pensamiento.

Considerar que el positivismo es una exageración y valorar el pensamiento utópico como necesario para el cambio histórico, no quiere decir que la autora de este ensayo no aprecie también los aspectos científicos de la obra de Marx. Me parece que sus planteamientos sobre las clases sociales, definidas en relación a la economía y por tanto, a la propiedad, así como su análisis pormenorizado del capitalismo como sistema económico, han sido bases 
muy útiles para el desarrollo teórico de las ciencias sociales en el siglo XX. Por ejemplo, en Filosofía Latinoamericana nos servimos del esquema de Marx para definir a la clase dominante en nuestros países en los siglos XVIII y XIX como clase criolla terrateniente, hacendada, heredera de los encomenderos del siglo XVI (los criollos), y distinguirla de la clase mestiza de ese momento histórico (los mestizos), cuya definición no se refiere al mestizaje biológico o cultural, sino al hecho socio-económico de que era un grupo emergente vinculado con las profesiones u oficios de la ciudad y con propiedades urbanas, que se alió a los criollos en la lucha contra el imperio español, por la autonomía primero y la independencia después de nuestras repúblicas.

Volviendo a la vinculación teórica entre liberalismo y socialismo, sostengo que, independientemente de las especificidades de los distintos momentos históricos y otras particularidades sociales o nacionales, no hay tanta diferencia entre las ideas de los autores del Manifiesto Comunista; pequeño-burgueses, dirían ellos mismos dentro de sus clasificaciones sociales, pero principales teóricos del socialismo o comunismo; y las de los otros pensadores europeos-modernos aquí mencionados: Moro, un humanista del Renacimiento; Rousseau, un liberal del siglo XVIII, y los socialistas utópicos. La tesis en común es que la igualdad política, aquello de que seamos iguales ante la ley, no basta, y debe convertirse en igualdad social aboliendo la propiedad privada.

Sin embargo, analizando con profundidad los textos, se puede sostener que estos autores se expresan en contra de la propiedad privada con el fin de extenderla. Seguramente ya hoy hemos captado el propósito oculto de este planteamiento moderno-clásico, cuando ya no hablamos de abolir sino de democratizar la propiedad privada. 
Se puede argumentar que el discurso de la abolición representa paradójicamente el deseo de que los desposeídos tengan la posibilidad de convertirse en propietarios.

\section{Igualdad, libertad y fraternidad}

Hago referencia a estos antecedentes para sostener que la igualdad política es el valor liberal por excelencia. Las libertades de opinión, prensa, asociación y cultos, son efectos de ella, y la actitud fraterna se daría por añadidura.

Si recordamos la importancia de la igualdad política en el liberalismo, resulta menos sorprendente notar la cercanía teórica con el socialismo. Ésta es la clave para captar la vinculación entre estas filosofías políticas europeas-modernas. El pensamiento socialista o comunista del siglo XIX (filosóficamente se pueden usar como sinónimos) surgió con la motivación de superar los obstáculos socio-económicos, que seguían impidiendo la realización de los valores liberales.

Seguramente alguien pensará que la diferencia entre estas dos ideologías radica en la libertad de empresa, la iniciativa individual, la propiedad privada. Mi opinión es que tanto estas últimas, es decir, las libertades económicas como las libertades políticas, sólo están garantizadas en contextos sociales igualitarios.

El argumento es que, si la motivación del socialismo es superar los obstáculos que impiden la realización de los valores liberales, entonces no debería oponerse a las libertades, ni políticas ni económicas, aunque sostenga que el Estado regule la iniciativa privada para que no se produzcan abusos. Dicha intervención busca garantizar que los grupos menos favorecidos también tengan oportunidades. 
Realmente, tanto el liberalismo como el socialismo son ideologías propias del capitalismo. Con él surge la necesidad de que haya igualdad, entendida como igualdad de oportunidades. Tal noción no había existido en otros sistemas económicos. El capitalismo supone una sociedad de consumidores. Para que haya consumo, una proporción creciente de la población debe tener acceso a fuentes de trabajo, capacitación profesional; es decir, educación, y los otros aspectos indispensables para la conservación de la vida: alimento, vivienda, salud, esparcimiento. La conclusión lógica es que el empresario tendría que promover la igualdad de oportunidades, si quiere tener éxito en sus negocios. Tal vez la desigualdad de oportunidades sea una de las razones del poco éxito que ha tenido en el pasado el capitalismo nacional en los países de América Latina.

Los países comunistas del siglo XX también tenían, y algunos todavía tienen hoy, economías capitalistas. El comunismo o socialismo no es una organización económica, es una ideología política. El mejor ejemplo que se puede dar es el de la actual China Popular, cuyo gobierno sigue siendo comunista, aunque se haya abierto al libre mercado de una manera que podríamos llamar 'neoliberal'. Se puede afirmar en general que en los regímenes comunistas ha habido un capitalismo de Estado.

Marx y Engels no propusieron una nueva organización económica de la sociedad. En obras que escribió sólo, como El Capital, el primero de estos pensadores realizó un exhaustivo análisis crítico del capitalismo, pero no explicó una alternativa económica. La propuesta del $\mathrm{Ma}$ nifiesto Comunista es solamente política, es decir, que el proletariado tome el Estado, es decir, gobierne, para que se convierta en clase dominante. Cito:

El primer paso de la revolución obrera es la elevación del proletariado a clase dominante, la conquista de la demo- 
cracia. El proletariado se valdrá de su dominación política para ir arrancando a la burguesía todo el capital, para centralizar todos los instrumentos de producción en manos del Estado, es decir, del proletariado organizado como clase dominante, y para aumentar con la mayor rapidez posible la suma de las fuerzas productivas. Esto, naturalmente, no podrá cumplirse al principio más que por una violación despótica del derecho de propiedad y de las relaciones burguesas de producción. (Marx y Engels, 2005: 148).

En el texto anterior el término 'democracia' expresa el intento de superación de la desigualdad social. No tenían en cuenta Marx y Engels la importancia de la democracia formal, del voto universal y directo para elegir gobernantes e incluso para legitimar nuevas constituciones, como se lo ha hecho recientemente en varios países latinoamericanos. Al significado social de la palabra 'democracia' se debe que los Estados comunistas del siglo XX la hayan utilizado en algunos de sus nombres, por ejemplo, 'República Democrática Alemana', la cual era, como todos esos gobiernos, un régimen autoritario, es decir, no democrático en el sentido formal.

Ciertamente, los autores del Manifiesto afirman que 'al principio' será necesaria una 'violación despótica del derecho de propiedad'. Creían, pues, que el despotismo, la dictadura del proletariado, era un primer momento de la revolución, pero éste debía dar paso luego a una democracia que para que fuera completa, debía ser social y formal al mismo tiempo. La experiencia del siglo XX ha mostrado que la formalidad política no es menos importante que las 'condiciones materiales'. Me atrevo a sostener que en los países comunistas no se mejoró la vida de la mayoría de la población precisamente porque no había democracia formal. Esta última es la garantía institucional de la igualdad de oportunidades. 
Se podría argumentar que el 'socialismo del siglo XXI' en algunos países de América Latina, trata de reducir las barreras que impiden la igualdad de oportunidades, y maliciosamente se podría pensar que así incentiva al capitalismo. No olvidemos que este experimento político no pretende abolir la propiedad privada de los medios de producción, como fue declarada por los gobiernos comunistas del siglo XX. Por el contrario, el socialismo del siglo XXI mantiene en principio la democracia formal. No es lo mismo fortalecer al Estado para que éste proteja a los grupos menos favorecidos, con el fin de que haya igualdad de oportunidades, que eliminar toda iniciativa económica no estatal. Hoy sabemos que de esa manera los regímenes comunistas no lograron que la desigualdad social disminuyera realmente.

\section{Los malentendidos del siglo XX}

Pues bien, en el siglo pasado se realizaron revoluciones sociales, como había sido la Revolución Francesa en su tiempo, en países como Rusia, China o Cuba, en los que no había una clase igualitaria, la burguesía. Ahora pienso que tal vez los autores del Manifiesto Comunista tenían en mente esta característica cuando afirmaron que "la burguesía ha desempeñado en la historia un papel altamente revolucionario". (Marx y Engels, 2005: 102) Los regímenes que se establecieron después del cambio violento, se llamaron a sí mismos comunistas y declararon la abolición de la propiedad privada de los medios de producción.

También en el siglo XX sucedió que el juego de poder mundial llevó a la Unión Soviética a convertirse en el polo opuesto de los Estados Unidos de América en las relaciones internacionales y se produjo lo que se conoce como 'Guerra Fría'. Entonces, nos acostumbramos a opo- 
ner 'socialismo' o 'comunismo' a 'liberalismo', cuando en la historia europeo-occidental constituyen una continuación filosófica. Así lo ha sido realmente en algunas organizaciones políticas social-demócratas, por ejemplo, el gobernante Partido Socialista Obrero Español (PSOE) o el Partido Socialista de Chile, que también son liberales. Si algo interesante filosóficamente hablando pudiera implicar el socialismo del siglo XXI sería la decidida superación del comunismo o socialismo real del siglo XX, en cuanto régimen totalitario que no redujo la desigualdad social sino todo lo contrario. Es coherente con lo que vengo sosteniendo que los voceros del socialismo del siglo XXI se consideren continuadores del liberalismo latinoamericano.

En pocas palabras, la situación mundial influyó para que se tergiversara el contenido auténtico del pensamiento político, lo cual muestra la enorme importancia de las relaciones internacionales. Más allá de aquel juego de poder con su discurso ideológico, es necesario desentrañar la verdad: que los países comunistas tuvieron o tienen capitalismos de Estado con gobiernos totalitarios.

A esa confusión filosófica contribuyó la aparición del neoliberalismo en la segunda mitad del siglo XX, probablemente vinculada también al mismo tema geopolítico, con su idea de que toda regulación estatal es antiliberal. Por el contrario, esta tesis no es consecuente con los principios liberales, ya que justifica la desigualdad de oportunidades, considera que el Estado no debe regular la concentración de la riqueza, no debe impedir el monopolio. La reciente crisis financiera mundial ha mostrado que el capitalismo no puede funcionar sin regulación e intervención estatal.

En países como los de América Latina la influencia del neoliberalismo ha sido calamitosa, pues tratándose de sociedades que tienen todavía serios obstáculos para la igualdad de oportunidades, dicha ideología ha servido de 
pretexto para que ciertos grupos económicos continúen abusando de privilegios poco consecuentes con un estado de cosas liberal. Se debe identificar al neoliberalismo con el pensamiento conservador, que sí era en el siglo XIX una ideología que defendía los privilegios pre-liberales. Pero la palabra 'neoliberalismo' conduce a confusión.

\section{Conclusión}

Considero que la noción de igualdad política se basa en la idea de que los humanos real o convencionalmente diferentes, somos humanos en el sentido universal o abstracto de la palabra y por eso, iguales ante la ley. Históricamente, porque la burguesía europea tenía el interés de mostrar que cualquiera tiene el derecho de alcanzar poder, contamos con escritos que argumentan en contra de la desigualdad social. Ésa es la matriz teórica tanto del liberalismo como del socialismo o comunismo.

\section{Bibliografía}

DESCARTES, René

1971 Meditaciones Metafísicas, La Habana: Editorial de Ciencias Sociales.

DESCARTES, René

2007 Discurso del Método, Madrid: EDAF.

KANT, Immanuel

2005 Hacia la paz perpetua, un esbozo filosófico, Madrid, Biblioteca Nueva.

MARX, Karl, ENGELS, Friedrich

2005 Manifiesto del Partido Comunista, Buenos Aires: Longseller. MORO, Thomas

1984 Utopía, Barcelona: Ed. Planeta.

ROUSSEAU, Jean Jacques

1972 El origen de la desigualdad entre los hombres, México: Ed. Grijalbo. 